\section{A mind ever on the stretch}

\section{Robert Siegfried}

Thomas Beddoes MD 1760-1808:

Chemist, Physician, Democrat.

By Dorothy A. Stansfield.

Reidel: 1984. Pp. 306. Dfl.140, £35.75.

THOMAS Beddoes was not a great scientist. Nor did he occupy a public position that makes a biography obligatory. History has recorded his existence chiefly in the lives of Humphry Davy and Samuel Taylor Coleridge, both of whom benefited when young from his support and stimulation. But the range of Beddoes' active involvements was so great that his biography provides a fascinating perspective on major social, political and medical issues of late eighteenth century Britain. One obituary writer characterized him as the "physician whose mind was ever on the stretch". In the present work Mrs Stansfield has described all of Beddoes' activities with the aim "to see him whole"'.

A native of Shropshire, Beddoes was educated chiefly at Oxford, though he took his MD there in 1786 only after two years at Edinburgh. He stayed on as Reader in Chemistry until 1792. During those years he visited Lavoisier and de Morveau in France and became an early advocate of the "new chemistry". He wrote on the comparison of basalt and granite, finding evidence to support the Huttonian plutonic geology. Having taught himself Italian, French and German, he translated Spallanzani's Natural History (two editions), two major works of Torbern Bergman and Carl Scheele's Chemical Essays.

Beddoes moved from Oxford after his radical political views had made a chemical professorship unlikely. He quickly established a successful medical practice in Bristol and began planning the Pneumatic Medical Institution for the investigation of an aerial cure for pulmonary consumption. He was able to enlist the support of many prominent men, notably Thomas Wedgwood and James Watt, both of whom had personal reasons to hope for his success. The Institution opened its doors in 1798 with the young Humphry Davy as superintendent of the laboratory. The physiological properties of nitrous oxide (laughing gas) were the only discoveries of any note, but Beddoes' failure to exploit the gas's anaesthetic effect remains puzzling.

Beddoes was also busy writing tracts supporting a wide variety of liberal and progressive causes. He collected signatures petitioning for the abolition of the slave trade; he denounced with sometimes incoherent fervour government policies regarding France, and declared the war an unnecessary evil. More temperately he advocated equal educational opportunities for girls and boys, and wrote on the design of educational toys. After Davy's departure for London in 1801 he dedicated the Pneumatic Institution to the cause of preventative medicine, writing on the evils of drink, and producing medical guides and dietary advice for the poor.

In concentrating on Beddoes' own work, Mrs Stansfield has sometimes left the reader with an inadequate historical context by which to judge the originality or the uniqueness of Beddoes' contributions. But there is no uncertainty about his profound sense of humanity, and I am sorry that Mrs Stansfield did not make that quality the integrative theme of her biography. It could explain his failures as well as his ambitions, for he loved

\section{Cosmic magnetism}

\section{Leon Mestel}

Magnetic Fields in Astrophysics.

By Ya. B. Zeldovich, A.A. Ruzmaikin and D.D. Sokoloff.

Gordon \& Breach: 1984. Pp.365. \$80.

MAGNETOHYDRODYNAMICS - the study of the two-way interaction between the kinetic and magnetic fields in electrically conducting fluids - grew out of cosmical observations, beginning with the variations in the geomagnetic field, and the variety of phenomena grouped together as "solar activity". It is the large cosmical lengthscales which facilitate a strong interaction, for by Amperre's law a large-scale field is maintained by currents that are comparatively weak and so suffer far less Ohmic dissipation than in laboratory experiments. The subject is now an autonomous branch of fluid mechanics, but it is in the astrophysical context that one still finds the greatest variety of application.

Probably the most fundamental question is that of the origin and maintenance of cosmical magnetic fields. After a long period of doubt as to whether "dynamo action" was possible (due largely to results such as Cowling's "anti-dynamo theorem", which ruled out the simplest and most easily pictured field structures), there is now almost a plethora of models with a large-scale magnetic field that grows spontaneously via motional induction.

The present volume contains an extensive discussion of the conditions for dynamo action, starting with Faraday's unipolar inductor, crucially modified so that the currents induced in the rotating disk complete their circuit through a fixed helical wire, twisted in the same sense as the rotation. This simple model contains the two elements - differential rotation and helicity - that are typical of hydromagnetic dynamos (as anticipated in a seminal paper by E.N. Parker). The authors show considerable pedagogic skill humanity not wisely but too well.

There has been no major account of Beddoes since J.E. Stock's protective Memoirs of 1811. The usefulness of Mrs Stansfield's balanced biography is enhanced by extensive end-notes and a bibliography (somewhat idiosyncratic) of primary and secondary sources. There are two appendices; the list of Beddoes sixtyfive contributions to the Monthly Review between 1793 and 1801 is a most impressive testament to the range of his competency. Name and subject indexes complete this study of a man who saw so much more need in the world than he could meet.

Robert Siegfried is Professor of the History of Science at the University of WisconsinMadison.

in bringing out both the topological and analytical aspects of the problems; for example, they contrast the limitations of two-dimensional flows, which allow only "slow" dynamos, developing in time only by virtue of finite resistivity, with the greater potentiality of three-dimensionality, which in principle can yield "fast" dynamos that continue to operate at infinite magnetic Reynolds number.

Limitations on length have made inevitable a less detailed mathematical discussion of specific astrophysical problems, even of those that are direct applications of dynamo theory such as the cyclical magnetic activity shown by the Sun and detected in solar-type stars ("the solarstellar connection"). Still, the wideranging astrophysical reader will certainly find very useful the inclusion in one volume of chapters on the observational evidence for cosmical magnetism, and in particular for the galactic field, on magnetism and star formation, magnetic fields in cosmology, magneto-accretion by black holes, and on strong magnetic fields emanating from neutron stars.

The book remains to some extent personal in its emphasis - for example the authors say nothing about hydromagnetic stability, and little about the problems of the strongly magnetic early-type stars. There are also signs of somewhat hasty preparation in the occasional repetitiveness and premature reference to difficult concepts discussed subsequently. Nevertheless this is a very valuable addition to the literature, and one hopes that the publishers will soon offer the book in a more reasonably priced edition.

Leon Mestel is Professor of Astronomy at the University of Sussex.

- Peter and Jean Medawar's Aristotle to Zoos: A Philosophical Dictionary of Biology has now appeared in paperback. British publisher is Oxford University Press, price is $£ 4.95$. In the United States the paperback edition will be published in March by Harvard University Press. For review see Nature 308, 800 (1984). 